\title{
The dilemma of time: Student-centered teaching in the rural classroom in China
}

\author{
Dan Wang* \\ Runme Shaw Building 415, Faculty of Education, University of Hong Kong, Pokfulam Road, Hong Kong
}

\section{A R T I C L E I N F O}

\section{Article history:}

Received 4 December 2009

Received in revised form

18 June 2010

Accepted 26 July 2010

\section{Keywords:}

Dilemma of time

Student-centered teaching

Rural education in China

National curriculum

Classroom interaction

Rural-urban disparities

\begin{abstract}
A B S T R A C T
China has been promoting student-centered education under the current curriculum reform. However, teachers in rural schools continue to exercise tight control of the classroom, with lecturing taking up most of the class time. Drawing on ethnographic observation and interviews in a rural elementary school, this study analyzes the rationale of rural teachers in strategizing teaching methods. It has found that teachers' pedagogical choices are heavily constrained by both the centralized curriculum and schedule and the social context of rural-urban disparities. Together these constraints create a dilemma of time that significantly limits the room for teachers to experiment with student-centered methods.
\end{abstract}

(c) 2010 Elsevier Ltd. All rights reserved.

\section{Introduction}

China launched the quality education reform at the turn of the century. Central to the reform are curricular changes that aim at reducing student workload, cultivating higher-order skills, and encouraging all-round development (Feng, 2004). With respect to pedagogy, traditional lecturing and rote learning are to give way to student-centered teaching methods, such as small group work, discovery methods, and project-based inquiries (Dello-Iacovo, 2009). In rural areas, though recent research shows positive signs of teacher reception of the reform (Brock, 2009; Lam, 2009; Sargent, 2009; Sargent \& Hannum, 2009), most rural teachers continue to exercise tight control of the classroom, and lecturing takes up most of the class time (Wang, 2006). Drawing upon ethnographic observation and interviews in a rural school in Southwest China, this study is an attempt to analyze why rural teachers are reluctant to switch to student-centered teaching.

Studies in other countries have reported that time plays a significant role in teachers' decisions about teaching methods. Student-centered teaching tend to be more time-consuming and unpredictable than whole-class lecturing and teachers working under a fixed curriculum and schedule are inclined to organize the

\footnotetext{
* Tel.: +852 2859 1904; fax: +852 28585649 .

E-mail address: danwang@hku.hk.
}

class in a more teacher-centered manner to secure completion of required tasks (Alexander, 2000; Kennedy, 2005). The constraint of time is felt more strongly by teachers working with low-achieving students (Grant, 2009) and during educational reforms (Alexander, 2000).

This research confirms the findings in the literature that time is a crucial factor for teachers' pedagogical decisions. It underscores the dilemma of time as the key to understanding rural teachers' persistence in tight control of the class. Rural teachers in China are working under a national curriculum and schedule. The curriculum standards are set too high and the schedule too fast for poorperforming rural students. Therefore, rural teachers are in daily struggles to complete the basic content of the textbooks within the fixed schedule. The whole-class lecturing allows teachers to maintain the control of teaching pace and thus better secures completion of the textbooks than student-centered methods. In this context, teachers tend to continue with the old way of teaching not necessarily because they disagree with the reform ideals, but for protecting themselves from potential blames for their failure to cover the necessary content within the fixed timeframe. The author argues that the dilemma of time reflects both the cultural, economic, and educational inequalities between rural and urban children and the inherent contradictions within the reform itself, i.e. the conflict between the request for decentralized pedagogy and the persistence of a highly centralized curriculum and a fixed schedule. 


\section{The dilemma of time}

Alexander's (2000) study on pedagogy in five cultures has found that student-centered teaching is more time-consuming and unpredictable for task completion than teacher-centered approaches. Progressive teachers in England and the United States who enjoy more flexibility in the content and the pace of teaching, concern more about the time dilemma than teachers in Russia and India where curricula and school schedules are determined by the school, the region, or the central government. Research on the US teachers confirms the finding of the five-culture study (Kennedy, 2005). Kennedy (2005) emphasizes the difficulty of time management facing elementary teachers in the US. Teachers try to cede time to students for better intellectual engagement, which may digress from the class topic and jeopardize the completion of planned tasks. When task completion is threatened, teachers opt to resume control of the class time. For example, in one observation, a meaningful Q-and-A session is cut short abruptly when the teacher "suddenly noticed the clock." After class, she criticizes herself for doing that, but also admits that she is under high pressures because she is "far behind the textbook" (Kennedy, 2005). In other cases, teachers criticize themselves for giving an answer directly to students in order to "rush the lesson" or for dismissing students' inquiries in class that are thought to be off the script (Kennedy, 2005, p. 60). Such ambivalence indicates that time is experienced by these teachers as a dilemma in teaching.

In contrast, Russian and Indian teachers seem to be immune to the time dilemma since they are mandated to follow the lesson timeframe set by the school or the state (Alexander, 2000). In these cultures, little room is permitted for digressive engagement. Teachers are in firm control so the completion of tasks is predictable and secured.

Moreover, teachers' anxiety over time increases in periods of educational reforms. Time can become more problematic for progressive teachers if they are required to complete an overloaded curriculum, as in 1988 when the UK introduced a national curriculum (Alexander, 2000). Similarly, US teachers complain that the new accountability system has forced them to "teach very specific content according to very specific schedules" (Kennedy, 2005, pp. $169,215)$. These reforms tilt the precarious balance between the educational content and time, thus exacerbating the time dilemma experienced by progressive teachers.

Furthermore, students can be the most important circumstantial factor for teaching. In large and heterogeneous classes, as in the Indian case, rote learning is prevalent to keep children on task since "the spread of prior attainment was so wide" (Alexander, 2000, p. 424). A curriculum may be conceived as overcrowded only for particular groups of children in a student body of diverse achievement levels. For example, after the school reform in Raleigh, North Carolina of the United States, schools in the district all had to admit about $30 \%$ of low-income students. For these low-performing children, the teachers had to channel more resources behind them by doubling their study time because teachers in the regular class time had difficulties accommodating all students' learning paces (Grant, 2009, p. 113). The transformation of curriculum or the circumstances of students may request organizational innovations to address the time dilemma.

China, like Russia and Indian, has a national curriculum and fixed timetable, but is now rapidly reforming its curriculum and pedagogy in the recent decade toward a progressive ideal. The reform encourages diverse teaching strategies at the ground level, but maintains the centralized curriculum standards and a national timetable. In rural areas where students lag far behind their urban counterparts in academic performance, the introduction of more complex class activities in the teaching process may exert even higher pressure on time. In this background, this research article will investigate 1 ) how this curriculum reform influences rural teachers' experience of lesson time, and 2) whether and how their concerns over time advance the promotion of student-centered teaching in rural areas.

\section{Quality education reform}

Suzhi jiaoyu, usually translated into English as "quality education", was fully launched in China at the turn of the century. Since its debut in the mid-1990s, the concept of quality education has always been regarded as the antidote to the deficiencies of the examination-oriented education (yingshi jiaoyu) (Kipnis, 2006; Lu, 2005; MoE, 2005; Research-Group-One, 2006; Yuan, 2001) Examination-oriented education is considered to be the traditional knowledge-centered, domain-centered, and teacher-centered educational model (Zhong, 2005), while quality education represents its opposite, the modern trend of student-centered and inquiry-based education (Dello-Iacovo, 2009; Zhong, 2005).

In 2001, the Ministry of Education issued the "Guidelines for Basic Education Curriculum Reform (pilot) (jichu jiaoyu kecheng gaige gangyao (shixing))", referred to as the Guidelines below. The Guidelines lay out six objectives (Feng, 2006; MoE, 2001a) that can be categorized into three domains: changes in learning contents, pedagogical approaches, and school management. This paper principally focuses on the first two domains of the reform.

For the content of teaching, a new set of curricular standards were immediately promulgated also in 2001, specifying the learning contents and outcomes for each subject area in primary and secondary grades. The new standards were formulated with two clear intentions: one, to reduce the difficulty of learning contents in order to alleviate the workload of students, and the other to incorporate multi-domain integrative training for higherorder cognitive and social skills (Feng, 2004). Together with the stipulated subjects, a national timetable is also issued (MoE, 2001c) (see Table 1). New textbooks have been published in the spirit of these new standards and have gradually replaced the old versions of textbooks throughout the country, in urban and rural areas alike.

In terms of pedagogy, the Guidelines require that teachers actively interact with students in the teaching process to stimulate their motivation for learning. Teachers are expected to guide students to learn through hands-on activities like investigation and exploration. They are strongly urged to apply small group work, interactive teaching, and multimedia materials (particularly PowerPoint slides) in their classroom instruction. Indoctrination is clearly criticized, and new emphases are placed on student participation and on cultivating a spirit of innovation, practical skills, and individuality in students (Dello-Iacovo, 2009; MoE, 2001a; Yuan, 2001). The issuance of the Guidelines symbolized the arrival of a full-fledged progressive educational movement in China.

\section{The curriculum reform in rural China}

It has been widely reported that the curriculum reform has encountered a myriad of obstacles in rural schools (Qin, 2002; Wang \& Wang, 2005; Yang, 2007; Yang \& Yu, 2004). Teachercentered didactic teaching remains prevalent in rural classrooms although there is new evidence for promising improvement in Gansu and Shanxi provinces (Brock, 2009; Lam, 2009; Sargent, 2009). Wang's (2006) case studies of rural classrooms have found that teaching and learning methods remain unchanged. "In class, the principal way in which students learn is by sitting still and listening quietly, while teacher-controlled indoctrination is the main model of instruction. Learning is characterized by repeated 
Table 1

Curriculum and proportions of class hours for compulsory education.

\begin{tabular}{|c|c|c|c|c|c|c|c|c|c|c|}
\hline & \multicolumn{9}{|l|}{ Grade } & \multirow{2}{*}{$\begin{array}{l}\text { Sum of } \\
\text { nine-year } \\
\text { class hours } \\
\text { (percentage) }\end{array}$} \\
\hline & One & Two & Three & Four & Five & Six & Seven & Eight & Nine & \\
\hline \multirow[t]{10}{*}{ Subjects } & $\begin{array}{l}\text { Morals and } \\
\text { life }\end{array}$ & Morals and life & $\begin{array}{l}\text { Morals and } \\
\text { society }\end{array}$ & $\begin{array}{l}\text { Morals and } \\
\text { society }\end{array}$ & $\begin{array}{l}\text { Morals and } \\
\text { society }\end{array}$ & $\begin{array}{l}\text { Morals and } \\
\text { society }\end{array}$ & $\begin{array}{l}\text { Thoughts and } \\
\text { morals }\end{array}$ & $\begin{array}{l}\text { Thoughts and } \\
\text { morals }\end{array}$ & $\begin{array}{l}\text { Thoughts and } \\
\text { morals }\end{array}$ & $7-9$ \\
\hline & & & & & & & \multicolumn{3}{|c|}{$\begin{array}{l}\text { History and society (choose from: History or } \\
\text { Geography) }\end{array}$} & $3-4$ \\
\hline & & & Science & Science & Science & Science & \multicolumn{3}{|c|}{ Science (choose from: Biology, Physics, or Chemistry) } & $7-9$ \\
\hline & Chinese & Chinese & Chinese & Chinese & Chinese & Chinese & Chinese & Chinese & Chinese & $20-22$ \\
\hline & Math & Math & Math & Math & Math & Math & Math & Math & Math & $13-15$ \\
\hline & & & $\begin{array}{l}\text { Foreign } \\
\text { language }\end{array}$ & $\begin{array}{l}\text { Foreign } \\
\text { language }\end{array}$ & $\begin{array}{l}\text { Foreign } \\
\text { language }\end{array}$ & $\begin{array}{l}\text { Foreign } \\
\text { language }\end{array}$ & $\begin{array}{l}\text { Foreign } \\
\text { language }\end{array}$ & Foreign language & Foreign language & $6-8$ \\
\hline & P.E. & P.E. & P.E. & P.E. & P.E. & P.E. & P.E. and health & P.E. and health & P.E. and health & $10-11$ \\
\hline & \multicolumn{9}{|c|}{ Arts (choose from: art or music) } & $9-11$ \\
\hline & \multirow{2}{*}{\multicolumn{9}{|c|}{ Local and school based curriculum }} & $16-20$ \\
\hline & & & & & & & & & & \\
\hline $\begin{array}{l}\text { Sum of weekly } \\
\text { class hours } \\
\text { (period) }\end{array}$ & 26 & 26 & 30 & 30 & 30 & 30 & 34 & 34 & 34 & 274 \\
\hline $\begin{array}{l}\text { Sum of yearly } \\
\text { class hours } \\
\text { (period) }\end{array}$ & 910 & 910 & 1050 & 1050 & 1050 & 1050 & 1190 & 1190 & 1122 & 9522 \\
\hline
\end{tabular}

Source: The Ministry of Education (2001c). "Experimental Plan for the Curriculum of Compulsory Education."

reading and rote memorizing. Exams are administered every week, and students are ranked by their test scores. Teaching style is monotonous, and learning is boring." (Wang, 2006)

The current literature has suggested several factors contributing to the poor implementation of the new teaching methods. Firstly, low public investment in rural education has left rural schools short of material resources (Qin, 2002; Wang, 2006; Yu, 2002). The government has responded to the urgent needs for equipment and facilities by investing more than 10 billion Yuan to upgrade the IT facilities for rural education (Guang Ming Daily, 2007), but little effort has been devoted to building local capacities to use these technologies. Secondly, educational assessment still relies heavily on test scores and promotion rates (Wang, 2006; Yang \& Yu, 2004), which rules out the room for experimentation on new teaching methods.

Above all, teachers are viewed as the key barrier to the practice of student-centered methods. Some scholars blame rural teachers for their stubborn subscription to the "knowledge-centered", "teacher-centered", and test-oriented educational model (Meng \& Fan, 2004; Yang \& Yu, 2004). While recent studies have shown a higher degree of acceptance of quality education among rural teachers (Liu, 2007; Wang \& Wang, 2005), teachers are still seen as ill-adjusted to the changes in their role demanded by the reform (Xie, Shu, \& Liao, 2004). Other researchers see teacher competence as the major obstacle (Qin, 2002; Wang, 2006; Yang \& Yu, 2004). Rural schools are short of qualified teachers because of the low salaries (Yang \& Yu, 2004), and schools have to hire a considerable number of substitute teachers (daike jiaoshi). Young and capable teachers are unwilling to work in the under-developed rural regions, which means that the schools are left with aging and less competent staff (Research-Group-One, 2006; Wang, 2006).

As with previous reforms, teachers receive little support and are basically left on their own to handle the changes in the textbook and the curriculum (Marton, 2006). Rural teachers are the group who need professional development the most, but receive the least training opportunities (Lin, 2004; Yang \& Yu, 2004). For those few who do receive training, the training sessions are brief, general, and theoretical, and give little practical guidance on how to implement student-centered teaching in the classroom (Lin, 2004; Liu, 2007).

The current literature offers many hypotheses explaining the slow progress of the reform in rural schools, but empirical studies substantiating these hypotheses are scarce. In addition, while assessment, material resources, and professional development are important for teaching, the core activities of schooling take place within the class, which remains an under-researched domain. The triadic relationship among the teacher, the curriculum, and the students that is played out in daily classroom receives little attention. Time as a critical constraint that profoundly shapes teaching styles has hardly been studied. This study is an attempt to fill that gap by putting the time dilemma at the center of the analysis to understand rural teachers' pedagogical decisions in relation to the conditions of rural students and the curriculum reform at the national level.

\section{Fieldwork in Chaoyang Elementary School}

This study is part of an ethnographic study in a rural school, Chaoyang Elementary School, ${ }^{1}$ in Southwest China. The Chaoyang Township is under the jurisdiction of the county called Jinsan. Jinsan County is on the national list of impoverished counties, and Chaoyang Township is one of the poorest townships in this county. Chaoyang Elementary School is the only public school in the township. It consists of a central campus located close to the township government and 9 teaching points in villages called village schools. Chaoyang Elementary School is an "elementary school with a cap" - it has both elementary grades from grade one to grade six and junior high grades from seven to nine.

The school has 69 teachers and supporting staff serving 1700 students, village schools included. The central campus has about 1000 students and 50 teachers including 6 substitute teachers. More than half of the teachers are under 40 years old. About 600 students above 4 th grade board on campus on weekdays, while the rest commute everyday Most class sizes range from 60 to 80 students.

My fieldwork was conducted in the school from September 2006 to March 2007. I stayed on the central campus in the teachers' dormitory, followed their work schedule, ate meals together with them everyday in the small school canteen, and was assigned to

\footnotetext{
${ }^{1}$ Pseudo names are used for all participants, places, and the school to protect participants' privacy.
} 
teach one seventh grade subject, politics. Data were collected through observation, participant observation, and unstructured interviews with teachers and middle managers.

Altogether 39 classes were observed, digitally recorded, and later transcribed.

In addition to lesson observation, I spent most of my time in the two teachers' offices observing teachers' conversations and work outside class. The two offices provided me with a focused space, which automatically gave me access to almost all teachers. Interesting conversations and events usually took place in the offices. Most times, I took down quick bullet notes in my notebook, remembered the details by heart and waited until bedtime to recite the whole day's experience into an electronic recorder.

Approaches of the grounded theory (Glaser, 1978; Strauss \& Corbin, 1990) were employed for data coding and analysis after I had withdrawn from the field. When analyzing classroom teaching, teachers' complaints about the new curriculum, students, and pace emerged to be the three most prominent themes. I coded interviews, teacher conversations, and class observations according to these three themes. Then the themes were put together to analyze the constraints under which the teachers were working. In the analysis, time emerged to be the key to connect the three aspects of teaching experiences. The analysis was presented to one teacher in the school later for member checking and was confirmed by him.

In the following sections, I will present the curriculum and students as the constraints on classroom teaching in Chaoyang Elementary School, followed by a portrayal of one public math lesson that happens to showcase the interplays among the three themes to demonstrate the dilemma of time facing Chaoyang teachers.

\section{Results}

\section{1. "The new curriculum is good, but..."}

Teachers in Chaoyang Elementary School often remarked that the curriculum was unrealistic for rural students. One teacher said: "The new curriculum is good. It puts emphasis on cultivating creativity, students' independent skills of inquiry, habits of teamwork, emotional sensitivities. The new textbooks are much better compiled than the ones used before, more interesting, with more pictures, and diagrams. Well, they are good, but they are not realistic. Maybe they are suitable for city students, but certainly not for students here." This ambivalent pattern of "it is good, but..." always appeared whenever teachers talked about the new curriculum.

When pressed for specific reasons, some teachers admitted that the breadth of the textbook contents went beyond their professional preparation. Others expressed concerns about their lack of knowledge of how to design and implement classroom instruction with the new research-based discovery methods. However, the predominant reason cited was student quality. In the teachers' view, the new teaching methods were impractical because students in this mountain area were "backward, of low quality, could not adapt to and master fancy learning methods," and so on.

While I disagreed with teachers on their demeaning remarks about rural students, I also felt the sincerity in their comments teachers were not defending themselves by putting the blame on students. Apparently, their almost universal concern about students indicated that students were among the top difficulties teachers had to cope within their teaching. Then what specifically were the problems brough $\equiv$ o the teaching process by students? What caused these probleins? How did these problems affect the adaptation to the new student-centered teaching methods?

Answers to these questions were gradually unfolded through observation and my own experience of teaching in the school. The central obstacle turned out to be a struggle over time to keep up with the textbook that was caused by the mismatch between the state mandated curriculum and students' preparedness.

\subsection{Teachers and the curriculum: struggle over time}

Under the centralized educational system, Chaoyang teachers found their work largely decided externally by the state or by school administrators. The curriculum was determined by the central government, and prescribed textbooks were purchased from the market by the local educational bureau. Each semester, a teacher was held accountable for covering an entire textbook for his/her subject domain. Teachers' manuals, which came with the textbooks, would suggest appropriate class hours for each lesson. For the majority of teachers, the time suggested by teachers' manuals was insufficient to cover the content if they wanted to ensure the quality of learning outcomes. Time was a key index closely monitored by teachers and administrators. Around midterm, the school headmaster informally checked with teachers about their progress. In the weekly faculty meeting, he reminded the teachers: "Half of the semester will have passed by next week. Please pay attention to the teaching speed. Some of you are close to finishing while others are lingering on the first few pages."

Timely coverage of the textbook was necessitated by regular achievement exams. Although the central government in the past few years had been encouraging schools to remove or reduce the number of tests, exams were still administered in schools. These exams followed the pace of teaching suggested by the teacher' manuals, and therefore, they eventually functioned as a de facto mechanism to monitor the teaching speed. The textbook as an institutional control and teachers' anxiety about the speed were both fully revealed under the pressure of these exams. Exam papers were usually provided by the local educational bureau and other times purchased from the market to guarantee an objective evaluation, so to speak. For mid-term exams, Chaoyang Elementary School used the exam papers produced by the county educational bureau. One week before the exam, the chemistry teacher, Ke, walked angrily into the teachers' luncheon room and complained: "The headmaster told me that the mid-term exam on chemistry will cover 4 units of the textbook. I told him I have just finished 3 so far. Maybe those questions about unit four should be left out. He did not agree and scolded me for moving too slowly. What am I going to do? Fly through the unit in one week? Who the heck controls the pace of teaching, anyway? He or I? Speed is important, but quality also needs to be guaranteed."

Mismatches like this happened to this or that subject in monthly or mid-term exams, but they were tolerated, and negotiation was possible. However, every teacher had to catch up with the schedule one way or another by the end of the semester. The final exams were a hard measure by which teacher performance was compared and evaluated. By then, every teacher had to finish the assigned textbook or they would suffer blame and sometimes economic loss for poor exam scores. Consequently, teachers gave great weight to efficiency when strategizing their instructional approaches. Lecturing and rote learning were most effective for controlling the class tempo, and thus, the best way to ensure completion of the textbook.

\subsection{Curriculum and students}

Simply keeping up with the suggested pace of teaching was a problem for most of these rural teachers because the quantity of the teaching content was beyond the capacity of students from their early primary years. In 1996, a study evaluating the implementation of the previous round of curriculum reform in 1992 
reported rural teachers' feedback on textbooks used then (Tang, 2008). For students in poverty-stricken rural areas, both Chinese and math textbooks at primary level were considered to be unrealistically demanding. Students could not meet the learning requirements even though many rural schools scheduled far more classes than the curriculum allowed. One-third of rural Chinese teachers surveyed thought the number of Chinese characters to be taught was too much for lower primary grades in rural areas. Pinyin, the phonetics of the standard Chinese language, is critical for literacy and reading and also one of the two main tools for consulting a Chinese dictionary. However, only one month was assigned to cover pinyin in grade one as suggested by the 1992edition textbook. In practice, rural teachers had to take 8-10 weeks to teach pinyin. In rural Gansu, teachers estimated that grade two students could only master $50 \%$ of the characters required by the textbook. As a result of their poor achievement in language learning, students had great difficulties with applied math problems because they could not properly read and understand the context of the problems (Tang, 2008).

Although one of the objectives of the quality education reform is to decrease the difficulty and quantity of learning content, the new curricular standards issued in 2001 have not actually reduced the literacy requirement in lower primary grades very much. The Outline of the Chinese Curriculum in 1992 required 400 and 750 characters be taught in primary one and two respectively, a total of 1150 characters (Curriculum-and-Teaching-Materials-ResearchInstitute, 2001). In comparison, under the Chinese Curricular Standard in 2001, by the end of primary two, students are required to be able to write $800-1000$ characters, a reduction of between 150 and 350 characters. Nevertheless, the 2001 Standard also requires students to be able to read $1600-1800$ characters by the end of grade two (MoE, 2001b). Therefore, it is hard to judge if the workload for lower grade literacy has been reduced. During my fieldwork, a Chinese teacher from the best primary school in the county remarked that the workload for lower grade literacy has intensified under the new curricular standards. Even teachers in Beijing complain that the new textbooks contain far too much content to cover (Research-Panel, 2006). For Chinese language, a mere $20 \%$ of pilot schools in Beijing were able to keep the class time to within 6 lessons per week as required by the new curriculum, while for math, only $6 \%$ of the pilot schools met the requirement of 4-6 lessons each week (Research-Panel, 2006).

The unit on pinyin has even been shortened from one month to two weeks in the primary one Chinese textbook under the latest curriculum reform. The grade one Chinese teacher in Chaoyang Elementary School, Ms. Qu, was aware of the significance of pinyin and strived to "lay a solid foundation" for the children. Two months into the semester, I met her one day in the collective office. She told me anxiously, "You see, I have spent one month and a half on pinyin, but half of the students still cannot master it. Supposedly there are only two weeks for pinyin. I have over 60 children. That [the class size] slows me down as well." She opened the textbook and pointed to her teaching progress in the Table of Contents: "Half of the semester has passed, and I have only covered one-third of the textbook. How am I able to finish the book within the semester?"

The high requirements of the curriculum only make sense when the students are advanced urban children. Researchers have found that kindergarten experience has significant influences on children's academic achievement and motivation to learn in the elementary school (Arnold \& Doctoroff, 2003; Rao, Zhou, Sun, \& Zhang, 2010). In China, most urban children are sent to kindergarten as early as 3 years old, and by the time they enter the first grade at age 6 or 7, they have already learned simple reading, writing, arithmetic, singing, drawing, and dancing. An early childhood literacy study in Shanghai region found that before entering grade one, all children in the sample were able to read and write some words ( $\mathrm{Wu}, 2003)$. Children in the study knew 120 words on average when starting school. In the most advanced cases, children entered grade one already able to read more than 1200 characters; less than $15 \%$ of the surveyed children knew fewer than 20 characters (Wu, 2003, p. 68). Wu (2003) also argued that these initial gaps in literacy tend to widen in the following years of school learning. In contrast to urban families, the rural families in Chaoyang often times could not afford to send their children to a kindergarten, or did not have a kindergarten nearby. Moreover, rural kindergartens generally were of much lower quality compared with the urban ones. Without center-based early thild, education, students relied entirely on their families for school preparation. However, the average educational attainment for the rural population in the studied province was about 6 years (Gao \& Yang, 2004), and most of the better educated were working in urban factories and construction sites. Ms. Qu, quoted above, also pointed out how the lack of parental support slowed down her teaching: "Children don't do homework at home. I have already added an extra class in the afternoon for them to finish their homework before going home. Their parents don't care. Most moms and dads have left home for work in cities, and the children have been left with their grandparents. The grandmothers and grandfathers cannot help at all with the children's coursework. One boy even told me that his parents told him not to do homework! Therefore, I have to teach very slowly." In general, students were unlikely to receive help in academic studies from their families.

Disadvantaged by these economic, social, and cultural restraints, Chaoyang students needed more time to learn the same amount of knowledge and skills than their more advanced counterparts in urban settings. Also, the new textbook contained more objects, notions, and places that were unfamiliar to rural children, which demanded even more class time for explanation. Apparently, these practical barriers facing rural students were not taken into consideration when the curriculum was designed and textbooks compiled. In this sense, the urban-ryral disparities in economic, cultural, and human capital ha $\bar{\equiv}$ en ingrained in the new curricular standards.

\subsection{Classroom interactions: lecturing as defensive teaching}

The centralized national curriculum was an important if not the sole reason responsible for this poor achievement. Students in Chaoyang Elementary School persistently performed below grade requirement from the early primary years. As they moved up into higher grades, and new teaching contents accumulated over time, it became increasingly difficult for them to follow the teacher or to participate in class because of their weak foundation in the very basics of literacy and numeracy. According to a Chinese teacher working in the Jinsan county seat, urban students were trained to use the dictionary by grade three and were expected to learn the new words and phrases independently before coming to class. However, Chaoyang teachers in ninth grade still had to spend class time on demonstrating the pronunciation of new words in the textbook and explaining their meanings. Students did not have dictionaries, did not know how to use them because of a lack of proficiency in pinyin, or simply did not have the habit of preparing for class. In Chaoyang Elementary School, an achievement test in math for grade six returned an average score of 30 (out of 100) for all 200 or so students. More than 20 students had scores in the single digits, with the lowest one at 3.5. By junior high, more than half of the students could not read and write properly, or comprehend the basic meanings of the essays in the textbook.

Similar performances were found in other impoverished areas. A volunteer teacher reported that the writing of seventh graders in his 
school was fraught with spelling and grammar mistakes, and in some of the worse cases, students wrote without punctuation marks (Zhou, 2006). Wang and Li (2008) compared the learning effectiveness between rural and urban students in western China. Their study shows worrisome results that the performance of grade two and grade five students in their sample does not meet the minimum requirements of the curriculum. It is worth noting that while the curriculum standards are set too high for rural students to meet the basic requirements, urban teachers are observed to have increased the difficulty level in teaching by designing exercises and tasks that go beyond the requirements and suggestions of the mandated curriculum (Ma, Lam, \& Wong, 2006; Wang \& Paine, 2003).

Students brought into class their accumulated learning deficiencies, which significantly shaped the interactive dynamics in the classroom. Often, I saw the teacher ask a question in class, call on two or three students, and get the wrong answers, or many times, no answer at all except silence. The moments when students responded to the teacher with silence or with multiple "incorrect" answers were embarrassing to both the teacher and the students. The teacher would be looking around the classroom for any chance to make eye contact with students who might have the potential or eagerness to answer the question. However, the students all lowered their heads and eyes to avoid eye contact with the teacher. At this point, the teacher would have to make a decision whether to try another student, or provide the correct answer to save time. The deadlock had to be broken by someone, and it was usually the teacher who would provide the correct answer so that both the teacher and the students could be relieved, and the class could move on. These periods of stalemate took up valuable class time. If the teacher insisted on not giving out the answer directly, the deadlock would be unbearably prolonged, the teaching plan disrupted, and students would end up "learning nothing."

Giving out the answer directly did not necessarily mean that the students had actually "learned" anything. Nevertheless, "as long as one student in the class knows it [the content of teaching], it proves that I have taught it. I have done my job!" one teacher told me. An English teacher also said, "I won't call on the students in the back [of the classroom]. They would not understand a word, and there is no time for me to correct them. Or I will never finish any teaching plan. Therefore, I just make sure the top few can get by." A math teacher, Huang, expressed many times that he would only slow down for the top five or six students. Thus, the traditional "teachercentered" strategy served several functions: saving time, allowing some students a chance to "get it", and enabling teachers to fulfill the job requirement.

Most importantly, since poor test scores was practically unavoidable, covering all the required knowledge points became a key to deciding who should be held accountable for the failure. It was absolutely the teacher's fault if he or she failed to cover the mandated content. However, if teachers managed to teach all the prescribed knowledge points, regardless of the outcomes, they could claim that they had done their job, and the achievement of a few top students' could attest to this. In this case, the fault, at least part of it, was shifted onto students - it was the students who had not done their part. Caught between the overloaded curriculum and textbooks and students' disheartening performance, Chaoyang teachers opted for "preaching" as a defensive strategy.

\subsection{The student-centered classroom}

Lecturing enabled Chaoyang teachers to have better control of the pace of the lesson and allowed them to protect themselves in the conflict between the curriculum and students' preparedness. In contrast, with the new methods such as small group work, experiments, hands-on activities, and others, teachers would have to yield control of the classroom, perhaps, to no one because their students were not ready to take charge of a lesson at that time. In the end, teachers may risk not being able to accomplish the teaching tasks, thus exposing themselves to more blame. These risks were explicitly revealed in a demonstration lesson promoting student-centered teaching.

During my fieldwork, a public lesson was taught in Chaoyang Elementary School by a visiting teacher, Ms. Chan, from the county seat. The purpose of the lesson was to share teaching techniques of the new discovery methods and small group work. It was a math lesson in grade three on the topic of perimeter (zhou and zhouchang). ${ }^{2}$ There were more than 60 students in the grade-three class. To accommodate the lesson plan, only half of the class participated in the demonstration lesson. Students were organized into 6 groups and sat in circles facing each other.

The lesson was taught in an interactive way with clear goals to engage students in discovering the concept through hands-on activities. At the start of the lesson, Ms. Chan showed a picture in a frame. She had students identify the frame by feeling it and then introduced: "this is the new mathematic friend we are going to meet today. It is called perimeter (zhouchang)."

Then she referred to a picture in the textbook, which showed a boy asking his aunt to line the border of a rectangular tablecloth with laces. "Where do you want to sew the laces to this tablecloth?" Ms. Chan asked students.

"Here, here, here, and here." Students started to point in their own textbooks while talking to themselves.

"Raise your hand please." Ms. Chan requested.

A boy was then appointed to answer the question. He pointed to the sides of the rectangle and said: "here and here."

"What name would you give to it?" Ms. Chan probed.

"The rectangle," answered the student.

That of course was not the correct answer expected. So the teacher hinted: "What part of the rectangle?"

"Two sides," the student said; still not the right answer.

Ms. Chan pointed to each of the four sides of the rectangle and asked again: "you said put the laces here, here, here, and here. What do you call these parts of the rectangle?"

The student paused for a while and answered: "the length of the perimeter (zhouchang)."

The answer was still not accurate, but Ms. Chan gave up trying: "the length of the perimeter. Good. Please sit down."

Then she turned to the entire class: "We sew the laces to the borders of the rectangle, right?"

"Right." answered the class.

"What do we also call the borders of the rectangle? The perimeter (yi zhou). The perimeter is if we start from one point on one border of the rectangle, for example a point here," she raised the picture frame, indicated a point, and touched the frame slowly along the sides; "if we go through the circle of all sides, we will come back to what?" She went on answering herself: "The starting point. Now if we circle the borders of the rectangle once, what should we call it?"

"The starting point," students answered. It was a wrong answer again!

Mr. Chan repeated: "what do we call it if we line the rectangle from the starting point and then back to it?"

"The perimeter (yi zhou)." Students finally gave the right answer. Ms. Chan turned to the definition in the textbook and had students

\footnotetext{
${ }^{2}$ In English, the term perimeter refers to both the path and the length of it However, in Chinese, two separate terms are used. Zhou (or yi zhou used by the teacher, Ms. Chan, meaning one perimeter) refers to the path of the perimeter while
} zhouchang refers to the length of a perimeter. 
read it three times. Because Ms. Chan was unwilling to give the definition of perimeter directly, the introduction of the concept took about six minutes. In the next section, Ms. Chan gave more objects for students to "feel" $(\mathrm{mo})$ the perimeter so that they could develop a deeper impression of the concept. Students continued giving confused answers about the concept of perimeter and the length of a perimeter. Ms. Chan had to paraphrase or repeat each question several times in order to solicit the right answers from the children. By the time the class moved on to the measurement of a perimeter, $26 \mathrm{~min}$ had passed.

Group activities were designed for students to explore various ways of measuring objects of different shapes. Ms. Chan provided a tool kit for each group, including a cup, colored cotton strings, soft rulers, color pencils, and a candy box. Students were asked to work in groups to measure the perimeter of a textbook, a cup, a piece of paper, a desk, a candy box, and each others' wrists. It was the first time that students had been exposed to group work. Many of them sat still looking at each other, playing with the strings and tools, not knowing what to do. Ms. Chan walked around to guide the work of each group. However, she could only attend to one group at a time, and the rest of the students were left on their own while she was not present. The children's attention began to wander; they stopped listening, and gave more wrong answers to Ms. Chan's questions. Approximately $35 \mathrm{~min}$ were spent on measuring perimeters.

In the end, it took Ms. Chan one hour to carry out all the planned activities, but a regular class period was $45 \mathrm{~min}$ in Chaoyang Elementary School (and 40 min according to the national standard). After class, local math teachers informally checked with the best students in the class and found they could not distinguish the path of a perimeter (zhou) from the length of a perimeter (zhouchang). They commented on the lesson: "These new teaching methods won't work. A normal class has $45 \mathrm{~min}$. Her class took over one hour, and yet, the students did not quite understand the concept of perimeter. Not to mention she only had half of the class. With the full class size, she would get 12 groups. The class may well extend to two hours!"

It would be arbitrary to judge the effectiveness of activity-based teaching from this one lesson. Lecturing may not be superior to interactive teaching and group work in keeping student attention or having them understand the concept. Nonetheless, the interactive dynamics in class raised questions about the conditions of successful practice of the new participatory teaching. The format of student participation is easy to replicate, but it is the quality of their participation that matters. For example, it was easy to put students into small groups, but they were not necessarily doing their work. In this case, Ms. Chan finally ended up working with 6 sub-classes, which substantially prolonged the lesson. Moreover, the actual size of rural classes might render group work even more timeconsuming. Question-and-answer was another way to engage students. However, students' wrong answers took up a lot of time when Ms. Chan insistently avoided direct instruction on the concept of perimeter. Ideally, errors in the process of learning are natural and should be tolerated, yet under the time pressure to finish the pre-programmed textbook, it was a luxury for Chaoyang teachers to entertain fully students' mistakes in class. Through question-and-answer and small group work, Ms. Chan intended to yield part of the control over time to students, but the students were yet to be in the position to take the control of the class. Eventually, it was the teacher, Ms. Chan, who was criticized for the inefficient lesson.

\section{Conclusions and discussion}

This study supports the extant literature in arguing that time is an important factor to understanding teachers' pedagogical decisions (Alexander, 2000; Kennedy, 2005). Chinese rural teachers in the study are reluctant to adopt the new student-centered teaching methods because these new methods are more timeconsuming and unpredictable than lecturing. Teachers in the study are pressed on time to complete the state mandated curriculum that is overloaded for the low-achieving rural students and the student-centered approaches are likely to exacerbate the tension. They continue with whole-class lecturing and rote learning not because they disagree with the ideals of the reform, but for selfprotection, as it is easier to hold teachers accountable for failure to complete the textbook than for poor students learning outcomes. The dilemma of time signals the difficult situation where rural teachers are positioned between the mandated curriculum and ill academic preparation of the students.

The observation of Chaoyang Elementary School confirms the findings in the literature (Kennedy, 2005) that students are one of the most important circumstantial factors for teachers to decide on teaching strategies. In the context of rural China, due to the cultural and economic disadvantages, students have difficulties following the national curriculum schedule and meeting the basic performance requirements since early school years. So the cultural and economic disadvantages of students' family backgrounds are translated into a problem of time in the classroom.

While the conditions of students demand teachers to slow down in teaching, teachers on the other hand have to follow the national curriculum and the schedule of the textbook. The research agrees with the findings in the literature that the curriculum standards are currently set too high and the textbook schedule too fast for rural students (Tang, 2008). Whereas urban teachers try to add difficulty levels to the textbook content (Ma et al., 2006; Wang \& Paine, 2003), rural teachers are found struggling with bringing students to the minimum requirements of the textbooks. The time dilemma in the micro-level classroom reflects the social and educational inequality between urban and rural schools. A truly studentcentered education requires not only student-centered teaching methods, but also the content of learning that caters to the student academic preparedness and social backgrounds. The current curriculum reform liberates teachers in pedagogical decisions, but the uniform national curriculum and schedule are in sharp conflict with the decentralization of pedagogy in the rural context.

It is worth noting that the highlight of the time dilemma in the study is not intended to rule out other explanations for the slackened implementation of the new curriculum in rural China, for example the lack of professional development and the testing system. The fact that even an urban teacher selected for the public lesson did not handle the student-centered classroom appropriately sends an even stronger message for the urgent need of teacher professional upgrading. It is not merely a coincidence that teachers' growing acceptance and practices of the student-centered approaches found in rural Gansu and Shanxi are concurrent with heavily investment in and committed support for teacher professional development (Brock, 2009; Lam, 2009). However, although the professional development may ameliorate the tension of time, it is unlikely solve the problem alone so far as the contradiction remains between the centralized curriculum and wide scholastic disparities between urban and rural students.

Finally it has to be noted that the existence of the disparities between urban and rural students does not guarantee that the implementation of the curriculum reform be better in urban school than in rural areas. Urban schools are also found to persist in wholeclass lecturing and intensive drillings due to the high pressure of tests (Research-Group-Three, 2006). Nonetheless, test results per se do not emerge as the central concern of rural teachers in Chaoyang Elementary School because student scores are anticipated to be under par. With the doomed battle, the teachers strategize their 
pedagogical decisions not necessarily to improve test results, but with more intentions to excuse themselves from blames. This finding reminds us that even the seemingly similar teaching practices in urban and rural schools may have very different underpinnings behind the phenomenon.

As shown in the above discussion, the dilemma of time in the rural classroom teaching goes beyond the concern of pedagogy. It brings forth critical questions about educational inequalities in Chinese society in large as well as the contradiction inherent in the current round of curriculum reform, i.e. the contradiction between the centralized curriculum and schedule and the request for decentralized pedagogy. It is the hope that, from the vantage point of time, this article can open up new room for analyzing and understanding the interplay between the macro-level policies and social forces and the individual teachers' practices at the ground level.

\section{Acknowledgements}

I would like to thank the three anonymous reviewers for their valuable critiques on the manuscript. I am also grateful to Dr. Yanping Fang and Dr. Zongyi Deng for their comments and suggestions on the early drafts of the paper. Of course, it should go without saying that all errors are mine.

\section{References}

Alexander, R. (2000). Culture and pedagogy: International comparisons in primary education. Oxford: Blackwell Publishers Ltd.

Arnold, D. H., \& Doctoroff, G. L. (2003). The early education of socioeconomically disadvantaged children. Annual Review of Psychology, 54, 517-545.

Brock, A. (2009). Moving mountains stone by stone: reforming rural education in China. International Journal of Educational Development, 29, 454-462.

Curriculum,-and-Teaching-Materials-Research-Institute. (Ed.). (2001). 20 shi ji zhongguo zhong xiao xue ke cheng biao zhun, jiao xue da gang hui bian: yu wen juan. [20th Century curricular standards and teaching outlines: Chinese volume]. Beijing: People's Educational Press.

Dello-Iacovo, B. (2009). Curriculum reform and quality education in China: an overview. International Journal of Educational Development, 29, 241-249.

Feng, D. (2006). China's recent curriculum reform: progress and problems. Planning and Changing, 27(1-2), 131-144.

Feng, S. (2004). ke cheng gai ge: shi jie yu zhong guo. [Curriculum reform: World and China]. Guangzhou: Guangdong Educational Press.

Gao, S., \& Yang, X. (2004). zhong guo ren kou wen hua su zhi bao gao. [Report on the educational quality of Chinese population]. Beijing: Social Sciences Academic Press.

Glaser, B. G. (1978). Theoretical sensitivity: Advances in the methodology of grounded theory. Mill Valley, CA: Sociology Press.

Grant, G. (2009). Hope and despair in the American city: Why there are no bad schools in Raleigh. Cambridge, MA and London, England: Harvard University Press.

Guang Ming Daily. (September 26, 2007). 11.1 Billion Yuan to improve long-distance educational facilities for rural primary and secondary schools. Guang Ming Daily. Retrieved from. http://www.moe.edu.cn/edoas/website18/26/info33126.htm.

Kennedy, M. (2005). Inside teaching: How classroom life undermines reforms. Cambridge, MA and London, England: Harvard University Press.

Kipnis, A. (2006). Suzhi: a keyword approach. The China Quarterly, 186, 295-313.

Lam, S. (2009). Curriculum reform in a rural village: the experiment of Rural China Education Foundation. Positions: Dialogues on Education (4), 1-14.

Liu, J. (2007). chuan dong mou xian nong cun zhong xiao xue jiao shi xin ke cheng shi shi guan zhu cheng du de diao cha bao gao (shang). [Investigation report on rural primary and secondary teachers' level of concerns about the implementation of the new curriculum in a county in East Sichuan Province (part I)]. Jiaoyu Lilun yu Shijian (Educational Theories and Practices) (8), 47-50.

Lu, Y. (2005). Geng xin jiao yu si xiang guan nian, quan mian shi shi su zhi jiao yu. [Update educational thoughts and ideas, implement quality education thoroughly]. http://www.moe.edu.cn/edoas/website18/12/info17712.htm Retrieved 11.11.09.

Ma, Y.-p., Lam, C.-c., \& Wong, N.-y. (2006). Chinese primary school mathematics teachers working in a centralized curriculum system: a case study of two primary schools in North-East China. Compare, 36(2), 197-212.

Marton, A. M. (2006). The cultural politics of curricular reform in China: a case study of geographical education in Shanghai. Journal of Contemporary China, 15 (47), 233-254.
Meng, X., \& Fan, X. (2004). shi shu "xin ke gai” zai nong cun shi shi de zu li. [On obstacles of implementing the "new curriculum reform" in rural areas]. Zhongguo Nongye Jiaoyu (China Agricultural Education) (1), 1-3.

MoE. (2001a). ji chu jiao yu ke cheng gai ge gang yao (shi xing). [Guidelines for basic education curriculum reform (pilot)]. http://www.moe.edu.cn/edoas/website18/32/ info732.htm Retrieved 11.11.09.

MoE. (2001b). yu wen ke cheng biao zhun. [Curricular standards for Chinese]. http://www.being.org.cn/ncs/chn/chn.htm Retrieved 11.11.09.

MoE. (2001c). Experimental plan for the curriculum of compulsory education.

MoE. (2005). Suzhi Jiaoyu chronicle of events. http://www.moe.edu.cn/edoas/ website18/24/info16624.htm Retrieved 11.11.09.

Qin, Z. (2002). nong cun su zhi jiao yu de kun jing yu fan si. [Difficulties of and reflections on rural quality education]. Xiandai Zhong Xiao Xue Jiaoyu (Modern Primary and Secondary Education) (1), 1-4.

Rao, N., Zhou, J., Sun, J., \& Zhang, L. (2010). Early achievement in rural China: the role of preschool experience. Unpublished manuscript.

Research-Group-One. (2006). su zhi jiao yu de gai nian, nei han ji xiang guan li lun. [The concept, content and relevant theories of quality education]. In X. Zhu (Ed.), dui ce yu jian yi - 2005-2006 nian du jiao yu re dian, nan dian wen ti fen xi. [Countermeasures and suggestions: Analyses on educational hot issues and difficult problems in year 2005-2006] (pp. 23-31). Beijing: jiao yu ke xue chu ban she (Educational Science Press).

Research-Group-Three. (2006). xin shi qi su zhi jioa yu mian lin de tu chu wen ti yu ying shi jiao yu yu yan yu lie de yuan yin ji qi dui ce jian yi. [The problems of quality education in the new period and the causes and suggestions for the ever stronger presence of test-oriented education]. In X. Zhu (Ed.), dui ce yu jian yi2005-2006 nian du jiao yu re dian, nan dian wen ti fen xi. [Countermeasures and suggestions: Analyses on educational hot issues and difficult problems in year 2005-2006] (pp. 85-93). Beijing: jiao yu ke xue chu ban she (Educational Science Press).

Research-Panel. (2006). Teaching supervision and evaluation report on experimental subjects of Beijing basic education curriculum reform. Jiaoyu Yanjiu (Educational Research (3), 77-82.

Sargent, T. (2009). Revolutionizing ritual interaction in the classroom: constructing the Chinese renaissance of the 21st century. Modern China, 35(6), 662-691.

Sargent, T., \& Hannum, E. (2009). Doing more with less: teacher professional learning communities in resource-constrained primary schools in rural China. Journal of Teacher Education, 60(3), 258-276.

Strauss, A., \& Corbin, J. (1990). Basics of qualitative research: Grounded theory procedures and techniques. Newbury Park: California Sage.

Tang, X. (2008). jiu nian yi wu jiaoy yu xiao xuej jiao cai zai pin kun di qu shi yong qing kuang de diao cha yan jiu bao gao. [Research report on the use of nine-year compulsory education primary textbooks in areas of poverty]. Retrieved from. http://lw.china-b.com/ncjylw/lwzx_363553.html.

Wang, J. (2006). Difficulties and countermeasures in the implementation of qualityoriented education in rural primary and secondary schools. Jiaoyu Yanjiu (Educational Research) (11), 41-46.

Wang, J., \& Li, Y. (2008). Research on the quality of compulsory education teaching in western rural schools. Educational Research (2), 21-31.

Wang, J., \& Paine, L. W. (2003). Learning to teach with mandated curriculum and public examination of teaching as context. Teaching and Teacher Education, 19, 75-94.

Wang, J., \& Wang, L. (2005). The specific investigation into the current teaching method in the rural primary schools in Northwestern China. Curriculum Teaching Material and Method, 25(11), 15-20.

$\mathrm{Wu}, \mathrm{Z}$. (2003). xiao xue di nian ji xue sheng shi zi neng li de diao cha yu yan jiu. [Investigation and research on literacy of lower primary students]. Curriculum, Teaching Material and Method (10), 67-70.

Xie, Z., Shu, X., \& Liao, T. (2004). xin ke cheng shi shi xia nong cun jiao shi de shi ying xing wen ti. [Problems of rural teacher adaptation in the implementation of the new curriculum]. Jiangxi Jiaoyu Keyan (Jiangxi Educational Research) (11).

Yang, R. (2007). nong cn xian ji qu yu su zhi jiao yu zheng ce zhi xing guo cheng mo shi yan jiu. [A study on the process model of implementation of quality education policies at the rural county level]. Modern Education Science (14) $27-31$.

Yang, Y., \& Yu, J. (2004). nong cun xin ke cheng: wen ti yu dui ce. [New curriculum in rural areas: problems and solutions]. Jiaoyu Fazhan Yanjiu (Educational Development Research) (11), 19-21.

Yu, X. (2002). The urban-rural disparities in China's education: A cultural reproduction analysis. Nanjing: Nanjing University.

Yuan, G. (2001). su zhi jiao yu: 21 shi ji jiao yu jiao xue gai ge de qi zhi. [Quality education: the flag of educational and curriculum reform in 21 century]. http:// www.moe.edu.cn/edoas/website18/level3.jsp?tablename $=207$ \&infoid $=5771$ Retrieved 11.11.09.

Zhong, Q. (2005). Reconceptualization and curriculum innovation in China. Peking University Education Review, 3(1), 48-57.

Zhou, Y. (2006). xi bu zhi jiao de ri zi. [Days of volunteer teaching in the west]. In J. Zhou, H. Peng, \& Y. Zhou (Eds.), zou jin huang yang chuan. [Walking into Huangyangchuan] (pp. 97-231). Beijing: China Finance and Economics Press. 